\title{
A Box-Behnken design (BBD) optimization of the photocatalytic degradation of 2,4-dichlorophenoxyacetic acid (2,4-D) using $\mathrm{TiO}_{2} / \mathrm{H}_{2} \mathrm{O}_{2}$
}

\author{
Gamze Doğdu Okçua, Nazlı Baldan Pakdil ${ }^{a}$, Hatice Eser Ökten ${ }^{b}$, Arda Yalçuka,* \\ ${ }^{a}$ Faculty of Engineering and Architecture, Department of Environmental Engineering, Abant Izzet Baysal University, Golkoy \\ Campus-Bolu, Turkey, emails: ayalcuk@gmail.com (A.YYalçuk),dogdu.gamze@gmail.com (G.D. Okçu), pakdil_n@ibu.edu.tr (N.B. Pakdil) \\ ${ }^{b}$ Department of Environmental Engineering, Izmir Institute of Technology, 35420, Urla/Izmir, Turkey, email: haticeokten@iyte.edu.tr
}

Received 13 October 2017; Accepted 28 June 2018

\begin{abstract}
A B S T R A C T
2,4-Dichlorophenoxyacetic acid (2,4-D), a chlorinated phenoxy-alkanoic herbicide, is used extensively in agriculture. This work investigates $\mathrm{TiO}_{2} / \mathrm{H}_{2} \mathrm{O}_{2}$ mediated UV photocatalytic degradation of 2,4-D in a laboratory-scale photoreactor. Three levels of Box-Behnken design technique, combined with response surface methodology (RSM), were used to design the experiments. Two kinds of multivariate experimental design $\left(\mathrm{pH}, \mathrm{TiO}_{2}\right.$, and 2,4- $\mathrm{D}$ concentration) and $\left(\mathrm{pH}, \mathrm{TiO}_{2}\right.$, and $\mathrm{H}_{2} \mathrm{O}_{2}$ concentrations) were employed to establish two quadratic models (Model 1 and Model 2), showing the functional relationship between degradation rate of 2,4-D and three independent experimental parameters. Model 1 predicted optimum values for $\mathrm{pH}, \mathrm{TiO}_{2}$, and 2,4-D concentrations to be 5.7, $1.20 \mathrm{~g} \mathrm{~L}^{-1}$, and $32 \mathrm{mg} \mathrm{L}^{-1}$, respectively. Model 2 predicted optimum values for $\mathrm{pH}, \mathrm{TiO}_{2}$, and initial $\mathrm{H}_{2} \mathrm{O}_{2}$ concentrations to be $4.94,1.34 \mathrm{~g} \mathrm{~L}^{-1}$, and $161 \mathrm{mg} \mathrm{L}^{-1}$. Degradation rate of 2,4-D approached $78.10 \%$ for Model 1 and $83.63 \%$ for Model 2. For both models, similar results were obtained through optimizing variables by RSM and using single factorial batch reactor operation. Regression analysis showed good agreement between experimental results and predictive values for Models 1 and 2, with $R^{2}$ values of 0.9958 and 0.9976, respectively.
\end{abstract}

Keywords: 2,4-dichlorophenoxyacetic acid (2,4-D); $\mathrm{TiO}_{2} / \mathrm{H}_{2} \mathrm{O}_{2}$ photocatalysis; Box-Behnken design (BBD); Response surface methodology (RSM)

\section{Introduction}

2,4-Dichlorophenoxyacetic acid (2,4-D) is one of the most frequently used phenoxyacetic acid herbicides for controlling broadleaf weeds due to its high efficiency [1]. In many regions of the world, and especially in Turkey, 2,4-D is the most commonly used chlorinated phenoxy-alkanoic herbicide for a variety of agricultural activities - especially in potato, grain, and corn productions [2]. 2,4-D is considered moderately toxic by the World Health Organization. It is known to affect the nervous system of humans and animals and to act as a potential carcinogen, as an endocrine disrupter and as a mutagen. Since this compound exhibits high water solubility, mobility, and lifetime, its continuous

* Corresponding author. use may cause soil percolation, and surface and groundwater contamination [3]. The permissible amount of 2,4-D in drinking water is 0.1 and $70 \mu \mathrm{g} \mathrm{L} \mathrm{L}^{-1}$, according to the Turkish standard [4] and US standard [5,6], respectively. Being toxic and having the bio-refractory characteristics of the chlorophenoxy herbicides, advanced treatment methods are being developed to treat water contaminated with 2,4-D.

In recent years, by producing hydroxyl radicals $\left(\mathrm{OH}^{*}\right)$ through chemical, photochemical, photocatalytic, and electrochemical reactions, advanced oxidation processes have become a promising technology to eliminate pesticides from water systems $[7,8]$. Photocatalysis was observed to proceed via two different pathways: (1) generation of $\mathrm{OH}^{\bullet}$ from the holes present at valence band, and (2) direct oxidation of compound from valence holes [9]. Heterogeneous photocatalytic oxidation process relies on subsequently generating 
superoxide radicals $\left(\mathrm{O}_{2}^{-}\right)$and hydroxyl radicals $\left(\mathrm{OH}^{\bullet}\right)$, which are primary oxidizing species in photocatalytic oxidation processes [10-12].

Some examples for parametric optimization of photocatalytic degradation of organic pollutants in aqueous solutions, such as diuron, acrylonitrile, and chlorpyrifos, using the response surface methodology (RSM) have been previously reported [13-15]. However, these are mainly single-factor studies, based on change of a time-variable and they do not consider the effect of other variables in determining optimum conditions for photocatalysis. Since these studies neglect the combined effects of factors, accuracy of estimations is compromised in case a working parameter is changed [16]. The proposed multivariate method enables accurate estimation of response values and allows the optimal region for the studied process to be found in a shorter time and with lower chemical consumption. To the best of our knowledge, nor photocatalytic degradation of commercial grade 2,4-D herbicide, neither its parametric optimization via Box-Behnken Design (BBD) has been studied before. In this study, for the first time, $\mathrm{P} 25 \mathrm{TiO}_{2} / \mathrm{H}_{2} \mathrm{O}_{2} / \mathrm{UVA}$ facilitated 2,4-D photocatalytic degradation was investigated and further optimized using the RSM with BBD. RSM and BBD were used to optimize and analyze the effect of four operational parameters: $\mathrm{TiO}_{2}$ photocatalyst dose, the initial 2,4-D, pH, and $\mathrm{H}_{2} \mathrm{O}_{2}$ concentrations.

\section{Materials and methods}

\subsection{Chemicals and reagents}

All chemicals were used without further purification. Titanium (IV) oxide nanopowder (AEROXIDE ${ }^{\circledR} \mathrm{P} 25 \geq 99.5 \%$, $21 \mathrm{~nm}, 35-65 \mathrm{~m}^{2} \mathrm{~g}^{-1}$ (BET)) was used as the photocatalyst (Sigma Aldrich, Germany) due to its high performance in photocatalytic degradation reactions. Commercial grade Amin EXT 500 SL (equivalent to $500 \mathrm{~g} \mathrm{~L}^{-1}$ of 2,4-D) 2,4-D amine salt $\left(\mathrm{C}_{10} \mathrm{H}_{13} \mathrm{Cl}_{2} \mathrm{NO}_{3}, \mathrm{MW}: 266.12 \mathrm{~g} \mathrm{~mol}^{-1}\right)$ was from Agrofarm Company, Turkey. $\mathrm{NaOH}$ and $\mathrm{H}_{2} \mathrm{SO}_{4}$ (essay $97 \%$ ) were obtained from Merck, Germany. All solutions and reaction mixtures were prepared with purified water (Merck Millipore, Germany, spec. resistivity: $18.2 \mathrm{M} \Omega \mathrm{cm}$ ).

\subsection{Experimental procedure and analysis}

Photocatalytic experiments were performed in a $4.6 \mathrm{~L}$ (operating volume: $1 \mathrm{~L})$ cylindrical, $(14 \mathrm{~cm} \mathrm{D} \times 30 \mathrm{~cm} \mathrm{~L})$ batch photoreactor (Fig. 1) maintained at $22^{\circ} \mathrm{C} \pm 1^{\circ} \mathrm{C}$. The photoreactor was comprised of three parts: (1) an external Pyrex glass; (2) a Pyrex glass thimble, where the head part is fitted to outside container to form a gastight seal and running water is passed through the thimble to cool the reaction solution, and (3) an empty quartz chamber, in which a Philips PL-L UVA $36 \mathrm{~W}$ lamp (315-380 nm; $110 \mu \mathrm{W} \mathrm{cm} \mathrm{cm}^{-2}$ ) was placed. Reactor was also equipped with a control system, a water level sensor system and a water-inlet and outlet. A gas inlet opening supplied air from a diffuser system with $3.5 \mathrm{~L} \mathrm{~min}^{-1}$ capacity during experiments. Reactor was wrapped in aluminum foil to prevent UV ray penetration.

For irradiation experiments, 2,4-D solutions were prepared daily and upon addition of $\mathrm{TiO}_{2}$, reactor was stirred and air bubbled constantly for at least $30 \mathrm{~min}$ in the dark to allow the system to reach equilibrium in case of adsorption. This time was chosen so that under stirring in the dark no more herbicide molecules could be adsorbed by the photocatalyst. For comparison, irradiation experiments without $\mathrm{TiO}_{2}$ were also performed. The $\mathrm{pH}$ of reaction mixture was adjusted by adding $1 \mathrm{~N}$ of $\mathrm{NaOH}$ and $1 \mathrm{~N}$ of $\mathrm{H}_{2} \mathrm{SO}_{4}$ Photocatalysis efficiency was determined by withdrawing aliquots at specific

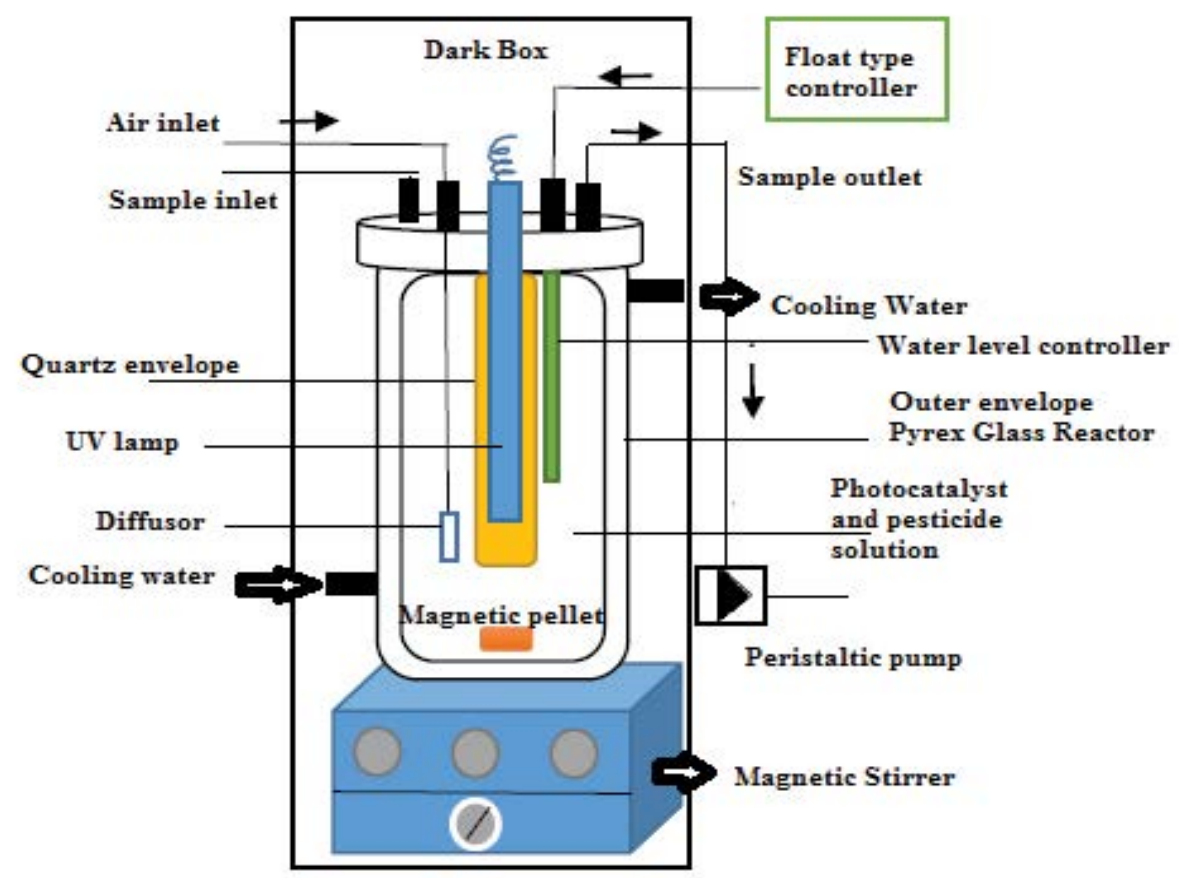

Fig. 1. Experimental setup of photocatalytic reactor. 
time intervals, where starting time was defined as the beginning of irradiation. Samples were filtered through $0.45 \mu \mathrm{m}$ filters (Millipore, Germany) to remove $\mathrm{TiO}_{2}$ from solution.

Optimization of photocatalysis conditions was initially done using a spectrophotometer (Shimadzu UV-1601-PC) and measuring the optical density (OD) of samples at its $\lambda_{\max }$ of $283 \mathrm{~nm}$, which is the given maximum absorption wavelength for 2,4-D molecules for $15 \mathrm{~min}$ irradiation. This was also confirmed by a spectrum reading from the spectrophotometer. Percentage of 2,4-D degradation was calculated using Eq. (1):

Percentage of degradation of $2,4-\mathrm{D}=\frac{C_{i}-C_{f}}{C_{i}}$

where $C_{i}$ and $C_{f}$ are the initial and final 2,4-D concentrations in the reaction mixture, respectively.

\subsection{Experimental design and statistical analysis}

RSM is a design technique that is used for optimization of process variables in multivariable systems by using experimental statistical methods. Even in very complex systems the relative importance of influencing factors is analyzed by combining mathematics and statistics. Therefore, once optimal conditions are determined by response surface method, not only study period is significantly shortened but also costs associated with the study are decreased [17]. Many RSM studies have been conducted to model experiments for analysis of photocatalytic processes [17-22]. The reason for choosing the Box-Behnken experimental design is to allow this method to efficiently evaluate multiple variables in each study test. Among all statistical experimental design methods, a BBD is a practical method for optimization studies because it requires fewer study sets than other design methods - such as 15 datasets for a 3-factor experimental design. Furthermore, the BBD method allows calculation of the response function at intermediate levels, which are not experimentally studied $[23,24]$. So, in this study, a statistical multivariate approach using two types of three-level, three-factorial BBD in combination with RSM was adopted to observe the photocatalytic process parameters affecting degradation efficiency of 2,4-D. While three parameters were set as independent variables, degradation efficiency of 2,4-D herbicide was the dependent response variable. Independent variable levels and ranges were presented in Table 1. Two optimization studies were conducted on the effect of $\mathrm{pH}$, $\mathrm{TiO}_{2}$, and $\mathrm{H}_{2} \mathrm{O}_{2}$ concentrations as the independent variables on the dependent 2,4-D degradation efficiency response variable. The factor levels were coded as -1 (low), 0 (central point or middle), and 1 (high). Independent variable value ranges were determined based on previous experimental studies and in order to maximize the 2,4-D removal. All analytical tests were carried out in triplicate. Second-order polynomials were used to represent experimental data to obtain the best-fit regression equations and to provide good predictions throughout the area of interest [14].

RSM was used for three variables in these experiments with a BBD [25]. BBD was adopted to evaluate the combined effect of the three independent variables from 15 sets of experiments of which 3 are repetitions at the center point.
Table 1

Experimental design levels of chosen parameters for two models

\begin{tabular}{|c|c|c|c|}
\hline Model 1 & \multicolumn{3}{|c|}{ Ranges and levels } \\
\hline $\begin{array}{l}\text { Independent } \\
\text { variables }\end{array}$ & Low $(-1)$ & Medium (0) & High $(+1)$ \\
\hline $\mathrm{pH}\left(x_{1}\right)$ & 3 & 5 & 7 \\
\hline $\mathrm{TiO}_{2}\left(x_{2}, \mathrm{~g} \mathrm{~L}^{-1}\right)$ & 0.5 & 1 & 1.5 \\
\hline $2,4-\mathrm{D}\left(x_{3^{\prime}} \mathrm{mg} \mathrm{L}^{-1}\right)$ & 10 & 30 & 50 \\
\hline Model 2 & \multicolumn{3}{|c|}{ Ranges and levels } \\
\hline $\begin{array}{l}\text { Independent } \\
\text { variables }\end{array}$ & Low $(-1)$ & Medium (0) & High $(+1)$ \\
\hline $\mathrm{pH}\left(x_{1}\right)$ & 3 & 5 & 7 \\
\hline $\mathrm{TiO}_{2}\left(x_{2}, \mathrm{~g} \mathrm{~L}^{-1}\right)$ & 0.5 & 1 & 1.5 \\
\hline $\mathrm{H}_{2} \mathrm{O}_{2}\left(x_{3}, \mathrm{mg} \mathrm{L}^{-1}\right)$ & 50 & 150 & 250 \\
\hline
\end{tabular}

The 2,4-D herbicide removal-yield dependent changed as a result of 15-min experiments. Degradation efficiency of 2,4-D herbicide resulting from 15-min experiments was the dependent variable. A second-order polynomial, Eq. (2), was used with nonlinear regression to fit experimental data and to identify relevant model terms. Considering all linear terms, square terms and linear-by-linear interaction terms, quadratic response model could be described as:

$$
\begin{aligned}
Y= & \beta_{0}+\sum_{i=1}^{k} \beta_{i} x_{i}+\sum_{j=2}^{k} \sum_{i=1}^{j-1} \beta_{i j} x_{i} x_{j}+\sum_{i=1}^{k} \beta_{i i} x_{i}^{2}+e_{i} \\
Y= & \beta_{0}+\beta_{1} x_{1}+\beta_{2} x_{2}+\beta_{3} x_{3}+\beta_{11} x_{1}^{2}+\beta_{22} x_{2}^{2}+\beta_{33} x_{3}^{2}+ \\
& \beta_{12} x_{1} x_{2}+\beta_{13} x_{1} x_{3}+\beta_{23} x_{2} x_{3}
\end{aligned}
$$

$Y(\%)$ represented the response variable (degradation efficiency of 2,4-D). $\beta_{0}$ was the interception coefficient, $\beta_{11}, \beta_{22}$ and $\beta_{33}$ were quadratic terms, $\beta_{12}, \beta_{13}$ and $\beta_{23}$ were interaction coefficients [25]. Since we ran two models $x_{1}, x_{2}$, and $x_{3}$ represented $\mathrm{pH}, \mathrm{TiO}_{2}$, and initial 2,4-D concentrations for Model 1 and represented $\mathrm{pH}, \mathrm{TiO}_{2}$, and initial $\mathrm{H}_{2} \mathrm{O}_{2}$ concentrations for Model 2. This equation only changed within studied intervals. Regression analysis and optimization processes were performed using Minitab 17.0 Statistical Software. Adequacy of designed models was assessed using "goodness of fit" and analysis of variance (ANOVA) techniques. The $p$ value of $<0.05$ for any factor in ANOVA test indicated a significant effect for corresponding variable on response. RSM was used to generate 3D surface plots from validated models. These surface plots were used to locate the optimum points for process parameters to deliver maximum degradation of the 2,4-D.

\section{Results and discussion}

\subsection{Model fitting and statistical analysis}

BBD is generally used for process optimization and it is very suitable for compatibility with quadratic surfaces [26]. Results from 2,4-D degradation efficiency experiments under various conditions are given in Table 2. As expected increasing $\mathrm{TiO}_{2}$ concentration when other variables were 
Table 2

Experimental values and predicted response

\begin{tabular}{|c|c|c|c|c|c|c|c|c|c|c|}
\hline \multirow[t]{2}{*}{ Run } & \multicolumn{3}{|c|}{ Experimental conditions } & \multicolumn{2}{|c|}{$\%$ 2,4-D degradation } & \multicolumn{3}{|c|}{ Experimental conditions } & \multicolumn{2}{|c|}{$\%$ 2,4-D degradation } \\
\hline & $x_{1} \mathrm{pH}$ & $\begin{array}{l}x_{2} \mathrm{TiO}_{2} \\
\left(\mathrm{~g} \mathrm{~L}^{-1}\right)\end{array}$ & $\begin{array}{l}x_{3} 2,4-\mathrm{D} \\
\left(\mathrm{mg} \mathrm{L}^{-1}\right)\end{array}$ & Experimental & Predicative & $x_{1} \mathrm{pH}$ & $\begin{array}{l}x_{2} \mathrm{TiO}_{2} \\
\left(\mathrm{~g} \mathrm{~L}^{-1}\right)\end{array}$ & $\begin{array}{l}x_{3} \mathrm{H}_{2} \mathrm{O}_{2} \\
\left(\mathrm{mg} \mathrm{L}^{-1}\right)\end{array}$ & Experimental & Predicative \\
\hline 1 & 3 & 0.5 & 30 & 25.974 & 25.281 & 3 & 0.5 & 150 & 37.703 & 51.250 \\
\hline 2 & 7 & 0.5 & 30 & 50.433 & 51.126 & 7 & 0.5 & 150 & 35.268 & 67.875 \\
\hline 3 & 3 & 1.5 & 30 & 54.113 & 53.420 & 3 & 1.5 & 150 & 55.492 & 43.625 \\
\hline 4 & 7 & 1.5 & 30 & 66.450 & 67.143 & 7 & 1.5 & 150 & 48.458 & 52.750 \\
\hline 5 & 3 & 1 & 10 & 27.273 & 27.413 & 3 & 1 & 50 & 42.167 & 36.313 \\
\hline 6 & 7 & 1 & 10 & 48.052 & 46.807 & 7 & 1 & 50 & 24.614 & 45.188 \\
\hline 7 & 3 & 1 & 50 & 35.325 & 36.569 & 3 & 1 & 250 & 32.900 & 90.812 \\
\hline 8 & 7 & 1 & 50 & 56.883 & 56.742 & 7 & 1 & 250 & 43.791 & 107.687 \\
\hline 9 & 5 & 0.5 & 10 & 23.377 & 23.929 & 5 & 0.5 & 50 & 56.169 & 40.438 \\
\hline 10 & 5 & 1.5 & 10 & 48.701 & 49.253 & 5 & 1.5 & 50 & 67.127 & 26.063 \\
\hline 11 & 5 & 0.5 & 50 & 37.273 & 36.721 & 5 & 0.5 & 250 & 60.227 & 95.937 \\
\hline 12 & 5 & 1.5 & 50 & 56.104 & 55.552 & 5 & 1.5 & 250 & 75.568 & 87.562 \\
\hline 13 & 5 & 1 & 30 & 73.593 & 73.882 & 5 & 1 & 150 & 84.091 & 69.667 \\
\hline 14 & 5 & 1 & 30 & 74.026 & 73.882 & 5 & 1 & 150 & 84.375 & 69.667 \\
\hline 15 & 5 & 1 & 30 & 74.026 & 73.882 & 5 & 1 & 150 & 83.631 & 69.667 \\
\hline
\end{tabular}

kept constant ( $\mathrm{pH}$ and initial 2,4-D concentrations for Model 1, $\mathrm{pH}$ and $\mathrm{H}_{2} \mathrm{O}_{2}$ concentrations for Model 2) increased 2,4-D degradation efficiency. The best degradation efficiency was measured in experiments and was predicted by Model 1 for pH 5 and values. Once $\mathrm{H}_{2} \mathrm{O}_{2}$ was included in experimental study the best degradation efficiency was observed for $\mathrm{pH}$ 5, $1 \mathrm{~g} \mathrm{~L}^{-1} \mathrm{TiO}_{2}$ concentration and $150 \mathrm{mg} \mathrm{L}^{-1} \mathrm{H}_{2} \mathrm{O}_{2}$ concentration values. On the other hand, the best prediction by Model 2 was given for $\mathrm{pH} 5,0.5 \mathrm{~g} \mathrm{~L}^{-1} \mathrm{TiO}_{2}$ concentration and $250 \mathrm{mg} \mathrm{L}^{-1}$ $\mathrm{H}_{2} \mathrm{O}_{2}$ concentration values.

The response functions generated for $Y_{1}\left(\right.$ Model 1) and $Y_{2}$ (Model 2), the percentage 2,4-D degradation using Eq. (3) are presented in Eqs. (4) and (5):

$$
\begin{aligned}
Y_{1}= & 73.882+9.892 x_{1}+11.039 x_{2}+4.773 x_{3}-3.030 x_{1} x_{2}+ \\
& 0.195 x_{1} x_{3}-1.623 x_{2} x_{3}-12.060 x_{1}^{2}-12.579 x_{2}^{2}-19.939 x_{3}^{2} \\
Y_{2}= & 84.032-2.017 x_{1}+7.160 x_{2}+2.801 x_{3}-1.150 x_{1} x_{2}+ \\
& 7.111 x_{1} x_{3}+1.096 x_{2} x_{3}-34.353 x_{1}^{2}-5.449 x_{2}^{2}-13.811 x_{3}^{2}
\end{aligned}
$$

For Eqs. (4) and (5), Y represented the percentage degradation efficiency of 2,4-D herbicide. Positive coefficients of $\mathrm{TiO}_{2}$ at both response functions implied an improvement in 2,4-D mineralization by residual catalyst loadings. Negative coefficient of initial $\mathrm{pH}$ in Eq. (5) indicated that mineralization was faster in an acidic medium with $\mathrm{H}_{2} \mathrm{O}_{2}$. López-Vásquez et al. [27] reported that free hydroxyl radicals attack the aromatic ring preferably on side chains at an acidic $\mathrm{pH}$, and 2,4-D degraded better in an acidic medium. In Model 1, quadratic terms of $\mathrm{TiO}_{2}$ concentration-initial 2,4-D concentration and $\mathrm{pH}-\mathrm{TiO}_{2}$ concentration had negative effects on herbicide removal. Likewise Model 2 demonstrated that quadratic term of $\mathrm{pH}-\mathrm{TiO}_{2}$ concentration also worked against the 2,4-D degradation. Consequently, their value-based increase in aqueous solution could lead to less herbicide degradation [28].
According to Eq. (4), there was a synergistic interaction between $\mathrm{TiO}_{2}$ and the initial $\mathrm{pH}$, and the highest synergistic interaction was obtained between the $\mathrm{pH}$ and $\mathrm{H}_{2} \mathrm{O}_{2}$ concentrations in the presence of $\mathrm{H}_{2} \mathrm{O}_{2}$. Moreover, interaction between 2,4-D concentration and initial $\mathrm{pH}$ was also significant. It was related to the anionic character of 2,4-D and its intermediates being favored by the attack orientation of oxidant species in an acidic medium [27]. López-Vásquez et al. [27] stated that the optimum conditions obtained from a flat plate photoreactor system were: $5.58,0.56 \mathrm{~g} \mathrm{~L}^{-1}$, and $30.41 \mathrm{mg} \mathrm{L}^{-1}$ for $\mathrm{pH}, \mathrm{TiO}_{2}$, and 2,4-D concentrations, respectively. Also, they mentioned that $66.87 \%$ 2,4-D mineralization was achieved, which was similar to the results obtained in this study.

\subsection{Analysis of variance}

The ANOVA for Model 1 and Model 2 was shown in Tables 3 and 4. Using an F-test, the lack-of-fit (variation of data around the fitted model) was evaluated. When ANOVA for empirical quadratic polynomial equation model was investigated, $p$ values were low $(<0.0001)$ for both models. $F$ values of Model 1 (369.99) and Model 2 (636.87), with a $p$ value less than 0.0001 , implied that models were statistically significant at $95 \%$ confidence level [29].

According to Model 1, $p$ values for coefficients $x_{1}, x_{2}, x_{3^{\prime}}$ quadratic coefficients $x_{1} x_{1}, x_{2} x_{2}, x_{3} x_{3}$ and influence coefficients $x_{1} x_{2}, x_{2} x_{3}$ were less than 0.05. Similarly, for Model 2, $p$ values for coefficients $x_{1}, x_{2}, x_{3}$, quadratic coefficients $x_{1} x_{1}, x_{2} x_{2}, x_{3} x_{3}$ and influence coefficient $x_{1} x_{3}$ were less than the 0.05 , emphasizing statistical significance of 2,4-D degradation efficiency. The effect of synergistic interaction between $\mathrm{pH}$ and 2,4-D concentration was statistically insignificant $(p>\alpha, \alpha=0.05)$ on 2,4-D herbicide removal for Model 1. For Model 2, effects of $\mathrm{TiO}_{2}-\mathrm{H}_{2} \mathrm{O}_{2}$ concentration and $\mathrm{pH}-\mathrm{TiO}_{2}$ concentration 
Table 3

ANOVA test responses for $Y_{1}$ (without $\mathrm{H}_{2} \mathrm{O}_{2}$ )

\begin{tabular}{|c|c|c|c|c|c|}
\hline Source & Sum of squares & Degree of freedom & Mean square & $F$ Value & $p$ Value \\
\hline Model & $4,262.31$ & 9 & 473.59 & 369.99 & $<0.0001^{\mathrm{a}}$ \\
\hline$x_{1}, \mathrm{pH}$ & 782.78 & 1 & 782.78 & 611.53 & $<0.0001$ \\
\hline$x_{2}, \mathrm{TiO}_{2}$ & 974.87 & 1 & 974.87 & 761.60 & $<0.0001$ \\
\hline$x_{3^{\prime}} 2,4-\mathrm{D}$ & 182.23 & 1 & 182.23 & 142.37 & $<0.0001$ \\
\hline$x_{1}^{2}$ & 353.97 & 1 & 537.01 & 419.53 & $<0.0001$ \\
\hline$x_{2}^{2}$ & 453.16 & 1 & 584.27 & 456.45 & $<0.0001$ \\
\hline$x_{3}^{2}$ & $1,467.88$ & 1 & $1,467.88$ & $1,146.76$ & $<0.0001$ \\
\hline$x_{1} x_{2}$ & 36.73 & 1 & 36.73 & 28.70 & $0.0030^{\mathrm{a}}$ \\
\hline$x_{1} x_{3}$ & 0.15 & 1 & 0.15 & 0.12 & 0.7450 \\
\hline$x_{2} x_{3}$ & 10.54 & 1 & 10.54 & 8.24 & $0.0350^{\mathrm{a}}$ \\
\hline Residual & 6.40 & 5 & 1.28 & & \\
\hline Lack of fit & 6.28 & 3 & 2.09 & 33.49 & $0.0290^{\mathrm{a}}$ \\
\hline Pure error & 0.12 & 2 & 0.06 & & \\
\hline \multirow[t]{2}{*}{ Total } & $4,268.71$ & 14 & & & \\
\hline & $R^{2}=0.9985$ & & $R^{2}($ pred $)=0.9764$ & $R^{2}(\operatorname{adj})=$ & \\
\hline
\end{tabular}

aStatistically significant

synergistic interactions on 2,4-D herbicide removal were statistically insignificant. The quadratic and interactive effects of variables would be lost if experiments were applied using conventional methods [30].

Lack-of-fit $F$-values were 33.49 ( $p$ value, $2.90 \%$ ) and 10.79 ( $p$ value, $8.60 \%$ ) for Model 1 and Model 2, respectively, and lack-of-fit- $F$ values were derived from noise by chance as only a $2.90 \%$ and $8.60 \%$ ratio. The coefficient of determination $\left(R^{2}\right)$ can be defined as the ratio of the considered variable to the total variation, and a measure of the degree of fit. The significance of a linear model is determined by the coefficient of determination $\left(R^{2}\right)$, the predicted coefficient of determination $\left(R_{\text {pred }}^{2}\right)$, and the adjusted coefficient of determination $\left(R_{\text {adj }}^{2}\right)$ [31]. When $R^{2}$ is close to 1 , the model fits the actual experimental data better [32,33]. As shown in Tables 3 and $4, R_{\text {pred }}^{2}$ and $R_{\text {adj }}^{2}$ were reasonably consistent with each other. Joglekar and May [34] suggested that, for a good fit, $R^{2}$ should be at least 0.80 . The $R^{2}$ values for these response variables were higher than 0.80 (0.9985 and 0.9991 for Model 1 and Model 2, respectively), which indicated that the regression model accurately explained the 2,4-D degradation process by $\mathrm{TiO}_{2} / \mathrm{UVA}$ and $\mathrm{TiO}_{2} / \mathrm{UVA} / \mathrm{H}_{2} \mathrm{O}_{2}$ photocatalysis. In addition to these, $R_{\text {adj }}^{2}$ values of Model 1 and Model 2 (Tables 3 and 4) proved that the Box-Behnken experimental design

Table 4

ANOVA test responses for $Y_{2}$ (with $\mathrm{H}_{2} \mathrm{O}_{2}$ )

\begin{tabular}{|c|c|c|c|c|c|}
\hline Source & Sum of squares & Degree of freedom & Mean square & $F$ Value & $p$ Value \\
\hline Model & $5,553.56$ & 9 & 617.06 & 636.87 & $<0.0001^{\mathrm{a}}$ \\
\hline$x_{1}, \mathrm{pH}$ & 32.53 & 1 & 32.53 & 33.58 & 0.0020 \\
\hline$x_{2}, \mathrm{TiO}_{2}$ & 410.10 & 1 & 410.10 & 423.26 & $<0.0001$ \\
\hline$x_{3}, \mathrm{H}_{2} \mathrm{O}_{2}$ & 62.77 & 1 & 62.77 & 64.79 & $<0.0001$ \\
\hline$x_{1}^{2}$ & $4,060.09$ & 1 & $4,357.47$ & $4,497.33$ & $<0.0001$ \\
\hline$x_{2}^{2}$ & 71.46 & 1 & 109.62 & 113.14 & $<0.0001$ \\
\hline$x_{3}^{2}$ & 704.27 & 1 & 704.27 & 726.87 & $<0.0001$ \\
\hline$x_{1} x_{2}$ & 5.29 & 1 & 5.29 & 5.46 & 0.0670 \\
\hline$x_{1} x_{3}$ & 202.25 & 1 & 202.25 & 208.74 & $<0.0001$ \\
\hline$x_{2} x_{3}$ & 4.80 & 1 & 4.80 & 4.96 & 0.0770 \\
\hline Residual & 4.84 & 5 & 0.97 & & \\
\hline Lack of fit & 4.56 & 3 & 1.52 & 10.79 & $0.0860^{\mathrm{b}}$ \\
\hline Pure error & 0.28 & 2 & 0.14 & & \\
\hline \multirow[t]{2}{*}{ Total } & $5,558.40$ & 14 & & & \\
\hline & $R^{2}=0.9991$ & & $R^{2}($ pred $)=0.9868$ & $R^{2}(\operatorname{adj})=$ & \\
\hline
\end{tabular}

aStatistically significant.

bStatistically insignificant. 
choice was correct in the statistical analysis of experimental studies.

A normal probability plot and histograms of the residuals for the degradation efficiency of 2,4-D are shown in Fig. 2(a) without $\mathrm{H}_{2} \mathrm{O}_{2}$, and with $\mathrm{H}_{2} \mathrm{O}_{2}$ in Fig. 2(b). The data points on this plot were close to a straight line, supporting the conclusion that the underlying assumptions of the analysis were satisfied [14]. In addition, histogram diagrams pointed out that the residuals were in the proximity of straight diagonal line. Therefore, the developed models were considered to be adequate since residuals for prediction of each response were low [14]. As shown in Table 3, all variables were statistically significant without interaction of $\mathrm{pH}\left(x_{1}\right)$ and initial 2,4-D concentration $\left(x_{3}\right)(p<0.05)$. According to Table 4 , the interaction between $\mathrm{pH}\left(x_{1}\right)$ and $\mathrm{TiO}_{2}\left(x_{2}\right),\left(x_{1} x_{2}\right)$, and the interaction between $\mathrm{TiO}_{2}$ concentration $\left(x_{2}\right)$ and $\mathrm{H}_{2} \mathrm{O}_{2}$ concentration $\left(x_{3}\right),\left(x_{2} x_{3}\right)$, were statistically insignificant $(p>0.05)$. $\mathrm{TiO}_{2}$ concentration and $\mathrm{pH}$ had a more significant effect than 2,4-D concentration on the 2,4-D degradation efficiency, according to single terms in the regression model in Table 3. Kaur et al. [9] stated that coefficient of $\mathrm{TiO}_{2}$ concentration was high, and that improved the degradation effect of $\mathrm{TiO}_{2}$ parameter. Furthermore, as shown in Table $4, \mathrm{TiO}_{2}$ concentration and later $\mathrm{H}_{2} \mathrm{O}_{2}$ concentration values had a more significant effect than $\mathrm{pH}$ on herbicide degradation. In addition, the synergistic effect of $\mathrm{pH}$ and $\mathrm{H}_{2} \mathrm{O}_{2}$ concentration was highly effective in herbicide removal.

\subsection{Optimization of multiple responses}

For Model 1, negative quadratic factors of catalyst load, initial herbicide concentration and $\mathrm{pH}$ in the polynomial expression confirmed that optimal concentrations of all parameters were intermediate values (around $1.20 \mathrm{~g} \mathrm{~L}^{-1}$, $32 \mathrm{mg} \mathrm{L}^{-1}$, and 5.70, respectively). Hence, very high and very low values for all parameters inhibited herbicide degradation. For Model 2, negative quadratic factors of catalyst load and peroxide concentration in the polynomial expression confirmed that the optimal concentrations of both parameters were intermediate values (around $1.34 \mathrm{~g} \mathrm{~L}^{-1}$ and $161 \mathrm{mg} \mathrm{L}^{-1}$, respectively). In this way, very high and very low values of $\mathrm{TiO}_{2}$ and $\mathrm{H}_{2} \mathrm{O}_{2}$ inhibited herbicide degradation [35]. Also, $\mathrm{TiO}_{2}$ was the most significant term $(F=761.60)$ for a single independent variable in the removal of herbicide in Model 1 and Model 2. However, in Model 1 it was closely followed by $\mathrm{pH}(F=611.53)$.

Fig. 3(a) shows the interaction of $\mathrm{pH}$ and $\mathrm{TiO}_{2}$ concentration on the removal efficiency of 2,4-D. Degradation rate of 2,4-D gradually increased when both $\mathrm{pH}$ value and $\mathrm{TiO}_{2}$ concentration increased; however, trend of 2,4-D degradation rate decreased when $\mathrm{pH}$ increased beyond the optimum level (pH 5) at varying experimental levels of $\mathrm{TiO}_{2}$. Herbicide degradation increased with the level of catalyst concentration increasing under a $\mathrm{pH}$ of 5 . A low amount of catalyst also resulted in a lower herbicide degradation percentage. Minimum herbicide removal was observed at low $\mathrm{pH}$ and low catalyst dose. Hence, at higher $\mathrm{pH}$ values, the oxidizing radicals were rapidly scavenged and they could not react with herbicide molecules [36]. Fig. 3(b) shows that degradation rate of 2,4-D increased when $\mathrm{TiO}_{2}$ concentration and initial 2,4-D concentration increased. However, degradation rate trend for 2,4-D decreased at high $\mathrm{TiO}_{2}$ concentrations and initial 2,4-D concentration. Interaction effects of $\mathrm{pH}$ value and 2,4-D initial concentration on the degradation rate of 2,4-D depicted a bell-shaped response surface (Fig. 3(c)). With the $\mathrm{pH}$ value and 2,4-D concentration up to optimum points, degradation rate approached the maximum level. Quadratic term of $\mathrm{pH}$ and initial 2,4-D concentration had a positive coefficient and their combined increase lead to faster herbicide degradation. As shown in Fig. 3(d), 2,4-D degradation increased at acidic
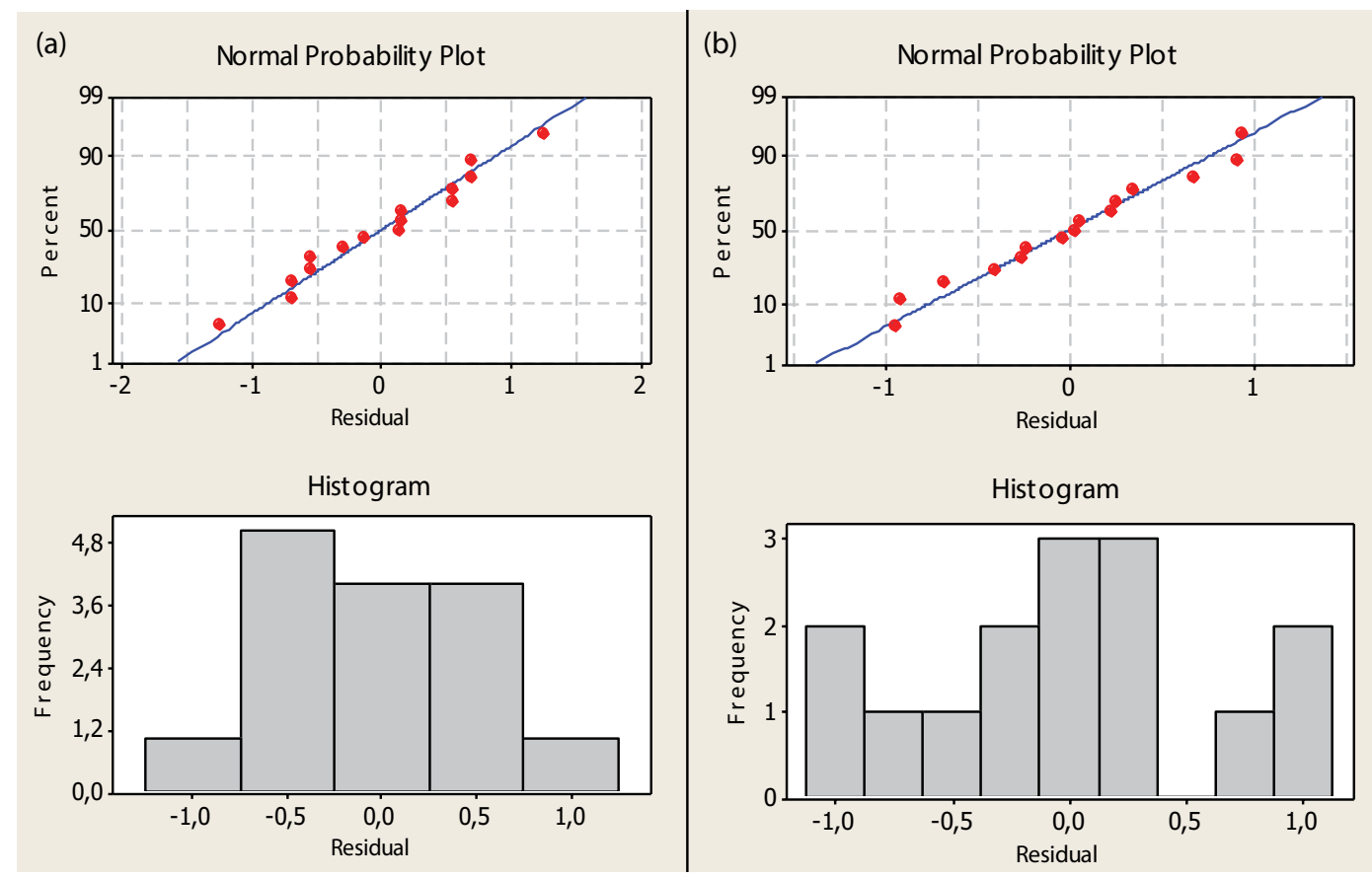

Fig. 2. Normal probability plot for percentage degradation and histograms of residuals (a) in absence of $\mathrm{H}_{2} \mathrm{O}_{2}$ (b) in presence of $\mathrm{H}_{2} \mathrm{O}_{2}$. 

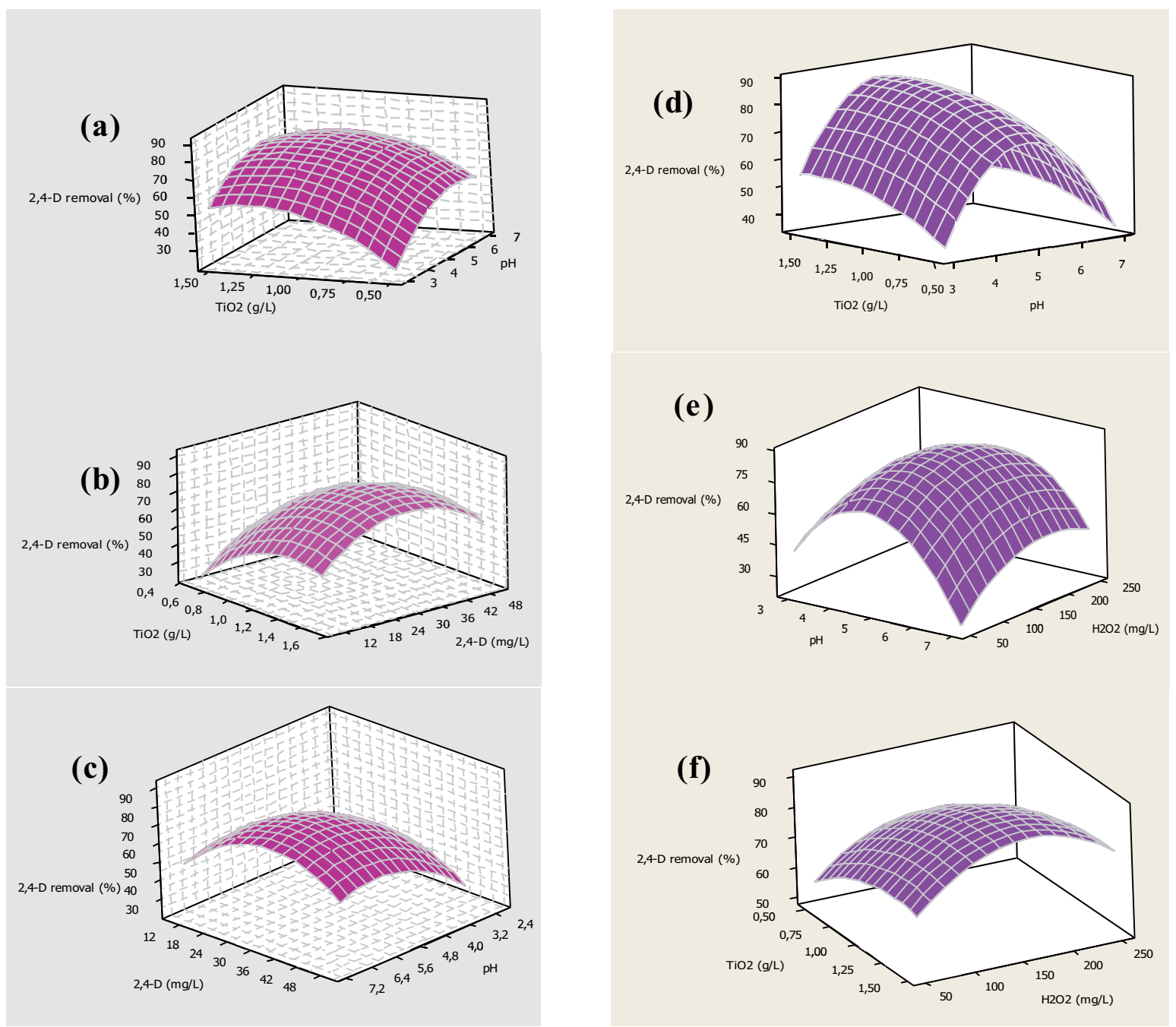

Fig. 3. Effect of $\mathrm{pH}, \mathrm{TiO}_{2}$ concentration, initial 2,4-D concentration and $\mathrm{H}_{2} \mathrm{O}_{2}$ concentration, on degradation efficiency of 2,4-D (a) initial 2,4-D concentration is constant at $30 \mathrm{mg} \mathrm{L}^{-1}$; (b) $\mathrm{pH}$ is constant at 5; (c) $\mathrm{TiO}_{2}$ concentration is constant at $1 \mathrm{~g} \mathrm{~L}^{-1}$. $\mathrm{Effect} \mathrm{of} \mathrm{pH}$, TiO $_{2}$ concentration, and $\mathrm{H}_{2} \mathrm{O}_{2}$ concentration on degradation efficiency of 2,4-D (d) $\mathrm{H}_{2} \mathrm{O}_{2}$ concentration is constant at $150 \mathrm{mg} \mathrm{L}^{-1}$; (e) TiO concentration is constant at $1 \mathrm{~g} \mathrm{~L}^{-1}$; (f) $\mathrm{pH}$ is constant at 5 .

region when $\mathrm{TiO}_{2}$ concentration increased. In Figs. 3(d)-(e), according to $\mathrm{pH}-\mathrm{TiO}_{2}$ and $\mathrm{pH}-\mathrm{H}_{2} \mathrm{O}_{2}$ surface plots, 2,4-D herbicide degradation increased with increasing $\mathrm{pH}$ and then the degradation decreased. At $\mathrm{pH}$ values lower than optimal, oxidation of organic contaminants was reduced due to less hydroxyl radical production. $\mathrm{H}^{+}$ion production could decrease and this lead to less hydroxyl formation under optimum $\mathrm{pH}$ conditions [15]. Removal of 2,4-D herbicide increased to a maximum point and then it began to decrease (Figs. 3(e)-(f). As expected, increase in $\mathrm{H}_{2} \mathrm{O}_{2}$ concentration removed radicals in aqueous solution, leading to a decrease in herbicide degradation.

\section{Conclusions}

This study showed the efficiency of photocatalytic degradation of 2,4-D when a $\mathrm{P} 25 \mathrm{TiO}_{2}$ catalyst and an $\mathrm{H}_{2} \mathrm{O}_{2}$ oxidizing agent was employed. The study clearly showed that BBD was an appropriate method to successfully optimize operating conditions for the photocatalytic degradation of 2,4-D.
The multivariate experimental designs were employed to establish two quadratic models showing the functional relationship between degradation efficiency of 2,4-D and four independent variables. For Model 1, the combined effect of a $\mathrm{pH}$ value of 5.70 , a $\mathrm{TiO}_{2}$ concentration of $1.20 \mathrm{~g} \mathrm{~L}^{-1}$, and an initial 2,4-D concentration of $32 \mathrm{mg} \mathrm{L}^{-1}$ yielded the highest degradation efficiency of $78.10 \%$. whereas for Model 2, the optimum condition yielding the highest degradation efficiency of $86.63 \%$ was a $\mathrm{pH}$ of 4.94 , a $1.34 \mathrm{~g} \mathrm{~L}^{-1}$ concentration of $\mathrm{TiO}_{2}$ and a $161 \mathrm{mg} \mathrm{L}^{-1}$ concentration of $\mathrm{H}_{2} \mathrm{O}_{2}$. For both models, optimum values obtained from the BBD process were in agreement with the single factor batch photocatalysis process results $(\mathrm{pH}$ of 5 , $1.5 \mathrm{~g} \mathrm{~L}^{-1}$ concentration of $\mathrm{TiO}_{2}$, an initial 2,4-D concentration of $25 \mathrm{mg} \mathrm{L}^{-1}$, and a $150 \mathrm{mg} \mathrm{L}^{-1}$ concentration of $\mathrm{H}_{2} \mathrm{O}_{2}$ ).

\section{Acknowledgments}

This study was financially supported by AIBU Scientific Research Project Number: 2016.09.02.1032. The authors would like to thank TUBITAK for the Ph.D. Dissertation Grant given 
to Gamze Dogdu Okcu within the 2211/A National Doctoral Scholarship Program.

\section{References}

[1] Y. Ordaz-Guillén, C.J. Galíndez-Mayer, N. Ruiz-Ordaz, C. Juárez-Ramírez, F. Santoyo-Tepole, O. Ramos-Monray, Evaluating the degradation of the herbicides picloram and 2,4-D in a compartmentalized reactive biobarrier with internal liquid recirculation, Environ. Sci. Pollut. Res., 21 (2014) 8765-8773.

[2] US EPA, Registration Eligibility Decision for 2,4-D webpage on EPA, Available at: https://archive.epa.gov/pesticides/ reregistration/web/pdf/24d_red.pdf, 2005.

[3] F.L. Souza, C. Saéz, M.R.V. Lanza, P. Canizares, M.A. Rodrigo, Removal of pesticide 2,4-D by conductive-diamond photoelectrochemical oxidation, Appl. Catal., B., 149 (2015) 24-30.

[4] Official Gazette, Turkish Regulation on Human Consumption Water, Part Four, Appendix-1, Chemical Parameters (25730), 17.02.2005, 19.

[5] National Pesticide Information Center, "2,4-D Technical Fact Sheet" webpage on EPA, Available at: http://npic.orst.edu/ factsheets/archive/2,4-DTech.html\#reg, 2016.

[6] WHO, The WHO Recommended Classification of Pesticides by Hazard and Guidelines to Classification, World Health Organization, Ginebra, 2004.

[7] M.A. Vishnuganth, R. Neelancherry, M. Kumar, N. Selvaraju, Carbofuran removal in continuous-photocatalytic reactor: reactor optimization, rate-constant determination and carbofuran degradation pathway analysis, J. Environ. Sci. Health, Part B, 52 (2017) 353-360.

[8] N.L. Finčur, J.B. Krstić, F.S. Šibul, D.V. Šojić, V.N. Despotović, N.D. Banić, J.R. Agbaba, B.F. Abramović, Removal of alprazolam from aqueous solutions by heterogeneous photocatalysis: influencing factors, intermediates, and products, Chem. Eng. J., 307 (2017) 1105-1115.

[9] T.J. Kaur, A.P. Toor, R. Wanchoo, UV-assisted degradation of propiconazole in $\mathrm{a} \mathrm{TiO}_{2}$ aqueous suspension: identification of transformation products and the reaction pathway using GC/ MS, Int. J. Environ. Anal. Chem., 95 (2015) 494-507.

[10] M. Qamar, M. Muneer, Comparative photocatalytic study of two selected pesticide derivatives, indole-3-acetic acid and indole-3-butyric acid in aqueous suspensions of titanium dioxide, J. Hazard. Mater., 120 (2005) 219-227.

[11] M. Yeber, E. Paul, C. Soto, Chemical and biological treatments to clean oily wastewater: optimization of the photocatalytic process using experimental design, Desal. Wat. Treat., 47 (2012) 295-299.

[12] M.N. Chong, Y.J. Cho, P.E. Poh, B. Jin, Evaluation of titanium dioxide photocatalytic technology for the treatment of reactive Black 5 dye in synthetic and real greywater effluents, J. Cleaner Prod., 89 (2015) 196-202.

[13] E.C. Catalkaya, F. Kargi, Dehalogenation, degradation and mineralization of diuron by peroxone (peroxide/ozone) treatment, J. Environ. Sci. Health, Part A, 44 (2009) 630-638.

[14] P. Singh, A. Dhir, V.K. Sangal, Optimization of photocatalytic process parameters for the degradation of acrylonitrile using Box-Behnken design, Desal. Wat. Treat., 55 (2015) 1501-1508.

[15] P.S. Thind, D. Kumari, S. John, $\mathrm{TiO}_{2} / \mathrm{H}_{2} \mathrm{O}_{2}$ mediated UV photocatalysis of Chlorpyrifos: optimization of process parameters using response surface methodology, JECE, 6 (2018) 3602-3609.

[16] M.N. Chong, B. Jin, C.W.K. Chow, C. Saint, Recent developments in photocatalytic water treatment technology: a review, Water Res., 44 (2010) 2997-3027.

[17] J. Zhang, D. Fu, Y. Xu, C. Liu, Optimization of parameters on photocatalytic degradation of chloramphenicol using $\mathrm{TiO}_{2}$ as photocatalyst by response surface methodology, JES, 22 (2010) 1281-1289.
[18] J. Burbano, I. Cruz, J. Colina-Márquez, A. López-Vásquez, F. Machuca, Evaluation of zinc oxide-based photocatalytic degradation of a commercial pesticide, J. Adv. Oxid. Technol., 11 (2008) 49-55.

[19] S. Rashidi, M. Nikazar, A.V. Yazdi, R. Fazaeli, Optimized photocatalytic degradation of Reactive Blue 2 by $\mathrm{TiO}_{2} / \mathrm{UV}$ process, J. Environ. Sci. Health, Part A, 49 (2014) 452-462.

[20] N. Chaibakhsh, N. Ahmadi, M.A. Zanjanch, Optimization of photocatalytic degradation of neutral red dye using $\mathrm{TiO}_{2}$ nanocatalyst via Box-Behnken design, Desal. Wat. Treat., 57 (2016) 9296-9306.

[21] A. Suárez-Escobar, A. Pataquiva-Mateus, A. López-Vasquez, Electrocoagulation-photocatalytic process for the treatment of lithographic wastewater. Optimization using response surface methodology (RSM) and kinetic study, Catal. Today, 266 (2016) 120-125.

[22] A. Carabin, P. Drogui, D. Robert, Photocatalytic oxidation of carbamazepine: application of an experimental design methodology, Water Air Soil Pollut., 227 (2016) 122.

[23] S.V. Sastry, M.A. Khan, Aqueous based polymeric dispersion: Plackett-Burman design for screening of formulation variables of atenolol gastrointestinal therapeutic system, Pharm. Acta Helv., 73 (1998) 105-112.

[24] E. Hamed, A. Sakr, Application of multiple response optimization technique to extended release formulations design, J. Controlled Release, 73 (2001) 329-338.

[25] G.E.P. Box, W.G. Hunter, J.S. Hunter, Statics for Experiments: An Introduction to Design Data Analysis and Model Building, Wiley, New York, 1978

[26] R.H. Myers, D.C. Montgomery, C.M. Anderson-Cook, Response Surface Methodology: Process and Product Optimization Using Designed Experiments, 3rd ed., John Wiley \& Sons, Inc., New York 2009.

[27] A. López-Vásquez, J.A. Colina-Márquez, F. Machuca-Martínez, Multivariable analysis of 2,4-d herbicide photocatalytic degradation, Dyna, 78 (2011) 119-125.

[28] A.V. Schenone, L.O. Conte, M.A. Botta, O.M. Alfano, Modeling and optimization of photo-Fenton degradation of 2,4-D using ferrioxalate complex and response surface methodology (RSM), J. Environ. Manage., 155 (2015) 177-183.

[29] I.H. Cho, K.D. Zoh, Photocatalytic degradation of azo dye (Reactive Red 120) in $\mathrm{TiO}_{2} / \mathrm{UV}$ system: optimization and modeling using a response surface methodology (RSM) based on the central composite design, Dyes Pigm., 75 (2007) 533-543.

[30] M.B. Kasiri, H. Aleboyeh, A. Aleboyeh, Modeling and optimization of heterogeneous photo-Fenton process with response surface methodology and artificial neural networks, Environ. Sci. Technol., 42 (2008) 7970-7975.

[31] D. Baş, İ.H. Boyacı, Modeling and optimization I: usability of response surface methodology, J. Food Eng., 78 (2007) 836-845.

[32] R. Larson, B. Farber, Elementary Statistics-picturing the World, Pearson Education Asia Limited and Tsinghua University Press, Beijing, China, 2003.

[33] J.M. Utts, R.F. Heckard, Mind on Statistics, Thamson Learning Asia and China Machine Press, Beijing, China, 2002.

[34] A.M. Joglekar, A.T. May, Product excellence through design of experiments, Cereal Food World, 32 (1987) 857-868.

[35] H. Zúňiga-Benitez, C. Aristizábal-Ciro, G.A. Peñuela, Heterogeneous photocatalytic degradation of the endocrinedisturbing chemical Benzophenone-3: parameters optimization and by-products identification, J. Environ. Manage., 167 (2016) 246-258.

[36] B. Pare, D. Swami, P. More, T. Qureshi, T.R. Thapak, Mineralization of methyene violet dye using titanium dioxide in presence of visible light, Int. J. Chem. Sci., 9 (2011) 1685-1697. 